\title{
BERGSON E O "BERGSONISMO": UMA BREVE RECONSTRUÇÃO HISTÓRICO-CONCEITUAL
}

\author{
ADEÍLSON LOBATO VILHENA ${ }^{1}$
}

RESUMO: O pensamento de Bergson não se limita ao que se tem, recorrentemente, difundido como bergsonismo que, em larga medida, é resultado de livres interpretações, um tanto apressadas, de sua obra; faz-se necessário distinguir seu genuíno pensamento daquilo que se convencionou chamar de "bergsonismo". Com a abordagem dessa questão, trilharemos o percurso formativo do filósofo francês, destacando dois caminhos: positivismo e espiritualismo. Ambos deixaram marcas profundas no pensamento de Bergson, contudo, sem deixar que sua filosofia perdesse o aspecto de autonomia; nosso filósofo observa que aqueles caminhos também apresentavam graves problemas. O presente ensaio, portanto, busca apresentar o ritmo da constituição do pensamento bergsoniano, ao mesmo tempo em que tenta realocar a figura emblemática do filosofo francês nas discussões da filosofia contemporânea.

PALAVRAS-CHAVE: Bergson; Bergsonismo; Positivismo; Espiritualismo.

ABSTRACT: Bergson's thinking is not confined to what one has, recurrently, diffused as Bergsonism, which to a large extent is the result of somewhat hasty free interpretations of his work; It is necessary to distinguish Bergson's genuine thinking from what is conventionally called "Bergsonism." With the approach of this question, we will trace the formative course of the French philosopher, highlighting two paths: positivism and spiritualism, both left deep marks in the thought of Bergson, however, without letting his philosophy lose the aspect of autonomy; our philosopher notes that these paths also presented serious problems. The present essay, therefore, tries to present the rhythm of the constitution of the Bergsonian thought, at the same time that tries to relocate the emblematic figure of the French philosopher in the discussions of the contemporary philosophy.

KEYWORDS: Bergson; Bergsonism; Positivism; Spiritualism.

Os biógrafos ${ }^{2}$ que conviveram diretamente com Bergson nos fazem entender que o que encontramos de preciso e de sereno em suas obras emana de sua própria postura como professor, que inspirava inúmeros alunos e admiradores durante a sua ocupação da cadeira da

\footnotetext{
${ }^{1}$ Doutorando em Filosofia pela Universidade Estadual do Oeste do Paraná (UNIOESTE). E-mail: advilhena@yahoo.com.br.

${ }^{2}$ Referimo-nos aos que pertenciam ao círculo de alunos e amigos mais próximos de Bergson, como Vladimir Jankélévitch, Jacques Chevalier, Jean Guitton, Jacques Maritain, entre outros que além de narrarem a filosofia bergsoniana, se mantinham como testemunhas oculares da vida do filósofo.
} 
História da Filosofia Antiga no Collège de France. Ele fora retratado como um homem de poucas palavras, mas tomado por uma espiritualidade profunda. Enquanto se calava ao mundo exterior, era então absorvido por burburinhos em seu interior advindos de seus pensamentos. O silêncio que o apresentava era o reflexo de sua atividade ao esculpir, laboriosamente, seu pensamento. Certo mistério que o envolvia também pairava sobre suas obras, o que certamente tem levado seus interlocutores ao incansável desejo de desvendá-lo. Chevalier nos relata como era o clima emblemático dessa atitude:

\begin{abstract}
A pessoa do conferencista não era estranha ao seu êxito: um silêncio envolvia a sala, uma emoção secreta apreendia as almas [...]. A palavra é lenta, nobre e regular como a sua escrita, de uma segurança extraordinária e surpreendente precisão, com entonações carinhosas, musicais, e uma espécie de aspiração que dá um toque de flerte (CHEVALIER, 1960, p. 20).
\end{abstract}

Se Bergson ganhou notoriedade intelectual de maneira tardia, talvez isso se devesse ao pudor de ser mal compreendido, já que o que mais buscou na filosofia foi um ideal de precisão. Essa será sua empreitada como filósofo: a de salvaguardar a filosofia de certos equívocos que até o momento a fizeram refém. Dessa forma, não poderia desenvolver sua obra de outra maneira se não buscasse se resguardar de uma precisão necessária. Apesar, entretanto, de ter o sutil cuidado de expor suas reflexões com maior probidade intelectual, Bergson não conseguiu evitar a interpolação de seu pensamento pela postura interpretativa um tanto dúbia de seus contemporâneos, em particular pela recepção de seus trabalhos mais difundidos, como Ensaio sobre os Dados Imediatos da Consciência, Matéria e Memória e A Evolução Criadora. No primeiro, Bergson é visto como um psicologista. No segundo, verão um Bergson extremamente idealista e, por fim, no terceiro, impostam nele as pechas de evolucionista, vitalista ou mesmo biologista. É inegável que nosso autor tenha se relacionado com escolas que representavam tais doutrinas, mas, de modo algum, se limitou a elas. Seu pensamento, embora discuta com teses científicas, tem como fulcro de tratamento o âmbito de questões propriamente ontológicas, questões que, intuídas em sua essência, são relevantes aos domínios do acontecimento vital. O filósofo alude, sim, acerca de uma evolução da vida, como das vivências psíquicas, mas nem por isso pode ser considerado simplesmente um teórico da evolução ou um psicologista que descreve os fatos psíquicos. Seu interesse é bem mais abrangente ou, melhor, mais profundo: está aquém ou além das descrições científicas. Assim, muito mais que vitalismo, no caso da A Evolução Criadora, Bergson reabre outra perspectiva a fim de pensar a vida. 
Há muito mais nas desenvolturas da reflexão de Bergson do que setores fragmentados. Sua obra não pode ser classificada como um sistema fechado ou periférico; pelo contrário, por transitar em várias regiões do pensamento, esse movimento reflexivo torna-se um leque que se abre a fim de pensar o todo em suas manifestações puras, não de maneira vaga, seguramente, mas, insistimos em dizer, por apresentar certa linearidade, tornando-se uma estrutura coesa. Por outro lado, nessas linhas estruturais da filosofia bergsoniana também despontam alvos fáceis que deram origem a certos mal-entendidos. Contrariamente ao que buscava Bergson, algumas exegeses um tanto apressadas de seu pensamento conduziram-no para alguns "guetos interpretativos". Noutros termos, as inúmeras hipóteses extraídas de sua filosofia alocaram a Bergson escolas das quais ele está longe, bem longe de representar, resultando, portanto, numa caricatura esboçada sob várias facetas, conforme a conhecida apreciação avocada por Merleau-Ponty acerca do bergsonismo: "Há mais de um paradoxo no destino do bergsonismo" (MERLEAU-PONTY, 1991, p. 201).

Diante disso, afinal, interpelemos: haveria ou não diferenças mais sutis entre Bergson e o bergsonismo? Era o bergsonismo, como sistema, pretendido por Bergson ou fora apenas engendrado por meio de interpretações equivocadas?

Desse modo, pode-se compreender que o bergsonismo, mais que o conjunto do pensamento de Bergson, pode aqui se situar como o resultado das interpretações que dele se obtiveram. O "paradoxo" de que fala Merleau-Ponty (1991, p.202) pôs Bergson de um lado e o bergsonismo de outro:

O bergsonismo estabelecido deforma Bergson. Bergson inquietava, o bergsonismo tranquiliza. Bergson era uma conquista, o bergsonismo defende, justifica Bergson. Bergson era um contato com as coisas, o bergsonismo é uma coletânea de opiniões aprendidas.

É importante deixar claro que essa postura de Merleau-Ponty, no sentido de redescobrir Bergson ou que distingue Bergson de certo "bergsonismo", vem de um Merleau-Ponty posterior às suas impressões iniciais. Sob esse aspecto, basta observamos a menção feita a Bergson na Fenomenologia da Percepção, cujo debate travado tem como pano de fundo a questão do tempo. Ali, Merleau-Ponty se limita a uma crítica mais incisiva quanto a uma suposta posição psicológica bergsoniana. A célebre metáfora segundo a qual "o tempo faz bola de neve consigo mesmo" se torna uma fórmula cabal dessa linha interpretativa.

Mas o corpo permanece, para ele (Bergson), aquilo que nós chamamos de corpo objetivo, a consciência permanece um conhecimento, o tempo permanece uma série de 'agoras', quer ele faça 'bola de neve consigo mesmo', quer ele se desdobre em 
tempo espacializado. Portanto, Bergson só pode estender ou distender a série dos 'agora': ele nunca chega ao movimento único pelo qual se constituem as três dimensões do tempo, e não se vê por que a duração se aniquila em um presente, por que a consciência se engaja em um corpo e em um mundo" (MERLEAU-PONTY, 1945, p. 93-94).

A interpretação merleau-pontyana parece carecer de maior propriedade do pensamento de Bergson, já que o projeto desse, ali em jogo, não se faz simpático com os traços relatados por Merleau-Ponty no que sustenta, hipoteticamente, um psicologismo que se ocupa em espacializar o tempo da consciência. Bergson, pelo contrário, cultiva refutar as teorias fisiológicas da memória.

Em que pese, no entanto, o valor da crítica de Merleau-Ponty, fato é que Bergson compreende o tempo como estrutura ontológica, ou seja, como uma dimensão duradoura que parece estar em comunhão, portanto, com o ser como fonte de toda experiência tal qual é desenvolvida em Matéria e Memória.

Uma vez tomado de modo primário, o pensamento de Bergson parece isento de maior complexidade. É essa impressão, à primeira vista, que dera vazão a uma série de estereótipos incutidos, como espiritualismo, vitalismo, psicologismo e, com isso, imputando a clássica convenção de "bergsonismo". Na verdade, tal experiência de pensamento, como toda obra filosófica, contém hermeneuticamente suas próprias dificuldades, não se acomodando, pura e simples, em meros jargões ou rótulos. Uma visão desapropriada incute nessa obra algo que não lhe é compatível. O bergsonismo, em alguns aspectos, foi construído com base nessa ilusão, chegando, em alguns casos, a desconfigurar o pensamento de Bergson. Gillouin assim nos faz compreender: “[...] por seu acesso prazeroso e fácil à filosofia bergsoniana, pôde conseguir amadores, mas o fundo em si está tão hermeticamente fechado aos profanos" (GILLOUIN, 1928, p. 7). Isso para dizer que existe, sim, uma diferença entre o pensamento de Bergson e o que fizeram dele, sistematizando-o como "bergsonismo".

O bergsonismo tende a apresentar a filosofia de Bergson um tanto esfumada, uma vez que sua preocupação não é adentrar na essência mesma de seu pensamento, mas manter-se em sua superfície. Não há dúvidas de que o "psicologismo", o "espiritualismo", o "evolucionismo", dentre outras terminologias escolares, resultam desse típico enquadramento. Bergson transitou por essas escolas, mas não se ateve a elas. O que cabe compreender é que elas se tornaram referências fundamentais para o filósofo explorar para além de descrições científicas. Mais do que tudo, seu interesse apontava para a experiência mesma do real, sem carecer de mediações descritivas. Por isso, talvez por conta de uma leitura simplista de Bergson, o bergsonismo não conseguiu dar conta de seu autêntico pensamento cuja influência 
tornou-se indispensável, mesmo que de maneira não reconhecida, para diferentes escolas filosóficas.

Merleau-Ponty, no entanto, não deixará, mais tarde, de restituir outro estatuto ao pensamento de Bergson, dessa vez de uma maneira mais viva, especialmente preparando-lhe uma recepção ao seio do movimento fenomenológico de inspiração existencial. Nessa perspectiva estaria Merleau-Ponty reconduzindo Bergson para além das poeiras exegéticas que pairavam sobre ele. Assim, adverte o fenomenólogo francês:

\begin{abstract}
Se, portanto, tivéssemos sido grandes leitores de Bergson, e se tivéssemos bem mais pensado com ele, nós teríamos sido atraídos para uma filosofia, eu diria muito mais por meio dele, bem mais concreta, muito menos reflexiva daquela para qual nos orientava Brunschvicg. Pois bem: como, de fato, Bergson não era muito lido por meus contemporâneos, é certo que nós tivemos que esperar pelas filosofias da existência a fim de sermos capazes de aprender muito do que ele teria sido capaz de nos ensinar. É bem certo - como se percebe cada vez mais hoje em dia - que se tivéssemos lido Bergson mais de perto, teríamos aprendido coisas que têm sido consideradas dez ou quinze anos mais tarde para nós como descobertas pela própria filosofia da existência. (MERLEAU-PONTY, 2000, p. 253).
\end{abstract}

Merleau-Ponty passa a reconhecer a importância da filosofia bergsoniana até na forma, sob certos aspectos, de uma propedêutica do existencialismo francês, adquirindo, pois, outra tonalidade no quadro da filosofia contemporânea de expressão fenomenológica. A verdade é que Merleau-Ponty busca, de algum modo, reabilitar Bergson no seio de uma ontologia viva e expressiva. Em seu texto de 1959 (Bergson se faisant), além da singela e declarada homenagem a Bergson, também deixa clara outra posição da sua filosofia. Como ele mesmo coloca, chega a hora de "transcender uma primeira aparência do bergsonismo" (MERLEAUPONTY, 1953, p. 18); aparência essa que se sustentou pelas leituras que não levavam em conta a autenticidade dos elementos centrais que também teriam implicado os conceitos de duração e intuição.

Certo é que Bergson não teve o reconhecimento devido, particularmente se levarmos em conta a primeira tradição interpretativa da qual ele fora objeto de análise. Sua filosofia foi obscurecida ou, ainda, soterrada mesmo por quem dela se serviu, como é o caso do existencialismo francês (em especial o sartriano), que fez de Bergson um fundo silencioso, mas voltando sua atenção, particularmente, à fenomenologia alemã. De modo algum se pretende aqui ignorar o mérito da fenomenologia germânica, sobretudo, husserliana; pelo contrário, é louvável que o existencialismo francês deva a ela o que lhe é de direito, tampouco pretendemos, forçosamente, caricaturar Bergson como um existencialista, mas o provérbio bíblico aqui parece válido: "dai a César o que é de César". Isso, aliás, melhor permite 
compreender em que medida Bergson é merecedor de um reconhecimento no interior mesmo de um debate filosófico, cujo teor sustenta o que na França se chamou de existencialismo, uma vez que seu pensamento, a nosso ver, também se encontra como um pano de fundo incontestável.

Em O Ser e o Nada se observam traços irretocáveis dessa influência, particularmente no capítulo II, dedicado a um meticuloso exame da temporalidade. Ali Sartre avoca a dimensão temporal como "síntese original" de acontecimentos, o que, em linguagem bergsoniana, traduz-se por duração. Sartre deixa transparecer a herança bergsoniana no que diz respeito à ontologia temporal; não obstante, é claro, com suas devidas ressalvas, pois, acredita que o passado se caracteriza como um nada, mas que, em sua conjuntura, deveria ser significado. $\mathrm{O}$ que nos diz Sartre é que: “O único método possível para estudar a temporalidade é abordá-la como uma totalidade que domina suas estruturas secundárias e lhes confere significação" (SARTRE, 2011, p. 158). No limiar dessa questão, volta à cena a intuição, ocupando o papel de atribuir significância à totalidade temporal. Ora, isso parece não ser estranho ao método de Bergson.

Mesmo que tenha se embebido na fonte de uma filosofia como a bergsoniana, Sartre não tardou de a ela voltar suas costas, como parece ficar patente nesse juízo: “[...] a filosofia francesa, que nos formou, não conhece de modo algum senão a epistemologia" (SARTRE, 1947, p. 31). Sartre não conseguiu ver na filosofia de Bergson mais que uma teoria do conhecimento, que em si parecia satisfazer-se tão somente em descrever fatos psíquicos (imagens) originários da matéria, embora inerentes à consciência. Dessa maneira, o existencialista francês acabou por tornar-se um dos propagadores desse "bergsonismo" um tanto exacerbado.

Apesar das preocupações recorrentes de Bergson, no sentido de expor sua filosofia de uma maneira lúcida, os equívocos interpretativos sobre seus pensamentos foram inevitáveis. A propósito, é Bergson mesmo que já alertava, em 1934, quanto a certos mal-entendidos acerca de sua tese:

O primeiro capítulo de Matière et Mémoire, no qual consignamos o resultado de nossas reflexões sobre as "imagens", foi julgado obscuro por todos aqueles que tinham, em alguma medida, o hábito da especulação filosófica, e exatamente em razão desse hábito. (BERGSON, 2006a, p. 87).

De fato, em 1936 tal "hábito" levou Sartre a atribuir a todo o sistema bergsoniano um idealismo excessivo, que, em sentido último, materializava a noção de imagem na consciência. A obscuridade não foi por Sartre dissipada, bem ao contrário, foi, de alguma 
forma, alimentada. É por demais conhecida a célebre metáfora sartriana do "espírito aranha", que representa, no cenário da filosofia francesa em curso por cem anos de academicismo, certa atmosfera "espiritualista" de que tudo se dissolve à consciência. Pois bem: a figura de Bergson ficara, de imediato, associada a essa imagem.

Utilizando-se do jargão de que "conhecer é comer", Sartre diagnostica a ilusão a que aquela filosofia de "espírito digestivo", por muito tempo, se prendeu. Assim, nos diz: "Nós todos lemos Brunschvicg, Lalande e Meyerson, nós todos acreditamos que o Espírito-Aranha atirava as coisas em sua teia, as cobria de uma baba branca e lentamente as deglutia, reduzindo-as à sua própria substância" (SARTRE, 1947, p. 29). Essa referência sintomaticamente negativa, também a Bergson, se deve ao fato de pensar que esse autor, numa direção diversa de Husserl, põe a consciência como receptáculo da realidade, elevandoa ao patamar de um absoluto: "Você crê aqui reconhecer Bergson e o primeiro capítulo de Matéria e Memória. Mas Husserl não é de modo algum realista: esta árvore sobre sua ponta de terra fendida, ele não faz dela um absoluto que entraria, depois, em comunicação conosco" (SARTRE, 1947, p. 30).

É, sobretudo, ao primeiro capítulo da obra Matéria e Memória, de Bergson, que Sartre dirige sua crítica, naquilo que ela comporta à noção de imagem, uma vez que, em termos sartrianos, a imagem de que fala Bergson não perdeu seu estatuto de objeto de consciência, sendo, desse modo, não translúcida, como tão bem teria avistado Husserl. Sartre apresenta a filosofia de Bergson como desprovida da realidade. Mais como uma forma de solipsismo. O que salta aos olhos é que Sartre não atenta aos reais objetivos bergsonianos, mesmo afirmando, em seu escrito $A$ Imaginação, que faria um "exame atento das concepções de Bergson" para mostrar que o autor de Matéria e Memória, “[...] apesar do uso de uma terminologia nova, não oferece uma solução que lhe traz absolutamente nada de novo quanto ao problema da imagem sob seu aspecto clássico" (SARTRE, 1980, p. 35).

Pelo visto, parece que o objetivo de Sartre é atenuado. Ali se nota que a leitura que Sartre fez de Matéria e Memória foi pouco abrangente naquilo que realmente Bergson se propôs em mostrar. Bergson tampouco estava interessado em desenvolver uma psicologia das imagens, como pensou Sartre. Sua visada, no que toca à consciência, não é para descrever fatos psíquicos, menos ainda se aliar às teorias do conhecimento, mas, sim, esclarecer o dualismo tocante ao problema corpo-espírito, o que, no fundo, se encaminha bem mais para uma ontologia, uma vez que é levado pela hipótese da coextensão da consciência à vida. Diversamente do que pensou Sartre, a consciência, em Bergson, não "digere" o mundo. Seu 
papel consiste, fundamentalmente, em percepcionar o real sem perder seu caráter de memória e duração.

Postular que a filosofia de Bergson se reduz a um sistema ou modelo a mais de psicologismo é perder de vista o que, de fato, ele se propôs: não perder de vista a dimensão originária ou, se quiser, a concretude mesma das coisas, conferindo estatuto à imanência do movimento real, no fluir da vida em sua plenitude.

O pensamento de Bergson, diferentemente do que foi postulado por Sartre, apresenta características inteiramente novas, trazendo, pois, a ideia de experiência vivida enquanto duração, o que nos leva a reconhecer a sua importância como emblema para a constituição da filosofia contemporânea. Como tantos outros pensadores que compunham aquele período, a obra de Bergson produz reflexões que se estendem para muito além de um simples panorama psíquico-científico.

Sem perder de vista o pano de fundo que compõe seu cenário histórico, já que um filósofo é filho de sua época, o fato é que Bergson transitou por diferentes correntes filosóficas, o que implica dizer que sua formação intelectual inclinava-se para o que estava em voga na época. É partindo dessa premissa que vemos duas portas se abrirem para recepcionar Bergson em sua formação intelectual: o positivismo e o espiritualismo.

Para tanto, o clima intelectual que antecedia à sua filosofia no século XIX era de embate entre duas linhas de pensamentos: uma traçada por uma metafísica dicotômica de princípios idealista e materialista; outra sustentada por uma antimetafísica, de princípios positivistas.

Com o próspero desenvolvimento científico da época, talvez inspirado pelo ideal de generalização das ciências empíricas, criava-se uma metafisica de inspiração positivista na qual Taine ocuparia um lugar importante ao tentar conciliar a natureza do espírito com a da matéria. É isso que Bergson nos deixa patente ao reconstituir o cenário intelectual da França do século XVIII até o XX em seus escritos de 1915 (A Filosofia Francesa): "Taine quis aplicar ao estudo da atividade humana, sob suas diversas formas, na literatura, na arte, na história, os métodos do naturalista e do físico" (BERGSON, 2006b, p. 263).

Dessa forma, portanto, a tendência de generalização das ciências objetivas não tardaria a chegar. É nesse momento, inclusive, que as ciências humanas são fortemente inclinadas a empregar o método experimental em seu afã do ideal de cientificidade. A psicofísica passa a constituir um amplo campo de investigação epistêmico, principalmente por inaugurar o projeto de naturalização da consciência, projeto em voga e com o qual se buscavam explicar os dados da consciência pelo mesmo viés metodológico das ciências empíricas, isto é, como 
coisas justapostas. Sendo assim, a matéria passa a ser o elemento determinante da realidade, o que, aliás, se torna um modelo explicativo quando se trata de definir a própria consciência. Substituía-se, assim, o espiritual pelo material.

O Ensaio sobre os Dados Imediatos da Consciência, obra inaugural de Bergson, retrata bem a configuração desse cenário, que insistia em extenuar o campo das vivências espirituais: a consciência. Ali, Bergson expõe, sumariamente, a conduta das ciências empíricas como também lança crítica àquelas ciências que se propunham a tarefa de eliminar o vital por meio de análise e observações externas. Buscava-se, principalmente, por critérios experimentais, mas de base psicológica, um referencial para a consciência no mundo natural, isto é, no empírico.

É importante observar que o que está na tangente da questão é o princípio de universalização das ciências empíricas, ou seja, sua penetração também no campo considerado humano - o que se torna inevitável. A título de exemplo, é a própria psicologia, seguindo, de maneira muito próxima, a fisiologia, que, naquelas circunstâncias, resultou no que hoje se entende por psicofísica.

Nessa conjuntura problemática não deixa de ser oportuno destacar que o que sustentava o conjunto dos problemas que assolavam o século que recepcionou Bergson era a confusão metodológica entre princípios físicos e princípios espirituais. Isto é, difundiam-se os resultados das abordagens psicológicas como se fossem oriundos de fatos físicos, o que não deixa de ser impróprio à concepção psicológica de Bergson, uma vez que o filósofo vê a psicologia originalmente como forma de acesso aos dados mais imediatos de nossa consciência, não podendo, portanto, suportar o tratamento de um método que, analogicamente, segue as diretrizes numéricas.

Compreender, enfim, que os fenômenos psíquicos se reduzem a fenômenos físicos é, de alguma forma, supor que as manifestações do espírito - pensamento, vontade, desejo, paixão, etc. - sempre se reduzem a funções cerebrais. Ora, é precisamente esse princípio que é postulado pelos defensores da psicologia materialista. Tais teóricos descreviam os fenômenos psíquicos como se fossem derivados dos fenômenos físicos. Assim, a psicologia do século XIX equiparava a consciência ao próprio espaço, já que é só na extensão que se poderiam estabelecer quantificações de elementos ali justapostos. Quanto a isso, Bergson alerta:

Ora, a exterioridade é a característica própria das coisas que ocupam espaço, enquanto os fatos de consciência não são essencialmente exteriores uns aos outros, e só se tornam assim por um desenrolar no tempo, considerado como meio homogêneo. (BERGSON, 1988, p. 72). 
A polarização da consciência no campo externo, desse modo, era justificada pela tendência de quantificar os estados internos. Para a psicofísica, as volições, as sensações, os sentimentos, as paixões eram dignos de mensuração. Na contramão dessa posição metódica, Bergson observa que os dados da consciência (vivências puras; melhor dizendo, "vivências de duração") não podem ocupar tal espaço, já que não são quantidades, e sim qualidades. Isso implica na vivência do fluxo qualitativo, que é a duração, e na negação da postura da psicologia experimental de reduzir tal fluxo ao espaço homogêneo: "É que, quanto mais se desce nas profundezas da consciência, menos se tem o direito de tratar os fatos psicológicos como coisas que se justapõem" (BERGSON, 1988, p. 15-16).

Diante de tal problema, Bergson formula a seguinte questão: "Que pode haver de comum, do ponto de vista da grandeza, entre o extensivo e o intensivo, entre o extenso e o inextenso?" (BERGSON, 1988, p. 12). Ora, reduzir a consciência à condição de simples objeto de análise da psicofísica implica, erroneamente, tomar os dados internos ou espirituais como passíveis de aumento e de diminuição. Noutros termos, essa operação nada mais consiste do que em uma forma prosaica de espacialização da consciência.

A bem dizer, a psicofísica já assumira um lugar comum no contexto em que se encontrava Bergson. Parafraseando-o, pode-se afirmar que o próprio senso comum se fez psicofísico. Nesse contexto teórico, Bergson observa que o que ali se produzia era um sistema de ilusões, já que é precisamente em vista de uma confusão prestada pela psicofísica que se assegurava a substituição do interno pelo externo, tendo como método o critério de mensuração. Bergson dita o real objetivo da psicofísica: "Fatalmente devia chegar a altura em que, familiarizada com a confusão entre a qualidade e a quantidade, entre a sensação e a excitação, a ciência procuraria medir uma como mede a outra: tal foi o objetivo da psicofísica” (BERGSON,1988, p. 53).

Ademais, não é difícil de compreender que o cenário desenhado pela ciência da época punha em risco as mais sutis realidades espirituais, em prol da exaltação da matéria.

É assim que, simultaneamente a essa metafísica empirista, desenvolvia-se um idealismo que buscava sintetizar o universo por leis estabelecidas pela consciência. Noutras palavras, baseando-se na evidência da consciência, o pensamento tornava-se a verdadeira essência das coisas. Caía-se, desde então, num ponto extremo, no qual a matéria, tão somente, não passava de uma representação. A bem da verdade, já um século antes, Berkeley tornou-se um dos principais expoentes que inspirou esse modo de conceber a realidade. Bergson mostra a inconsistência do filósofo irlandês ao buscar contrapor-se ao radicalismo do materialismo: 
"Seu erro foi acreditar que era preciso, para isso, transportar a matéria para o interior do espírito e fazer dela uma pura ideia" (BERGSON, 2006c, p. 3). Em resumo: o que resultou da querela entre o materialismo e o idealismo foi o descrédito da metafísica. Isto é, levantava-se daquele embate uma atitude antimetafísica fundada em pressupostos positivistas. A filosofia então se limita, consideravelmente, a um gênero de discurso que encontraria legitimidade, por exemplo, no círculo do positivismo lógico da Escola de Viena.

A cultura intelectual da qual emerge Bergson é, incontestavelmente, o positivismo ${ }^{3}$, que é o cenário que perpassou o século XIX até à primeira década do século XX. Nessa transição imperava o ideal que fundava a ciência positivista como a única fonte de verdade concebida. Bastando-se a si mesma, tal ciência ignorava o que estivesse fora desse parâmetro canônico. A lógica de conhecimento postulada nessa época, portanto, termina por depreciar todo recurso à metafísica. Sendo esse o espaço cultural (de fogo cruzado) que envolve o pensador francês, não seria de se estranhar se Bergson sofresse alguma influência de seu século, e assim o foi. Parafraseando Martins (1946, p. 10), pode-se considerar que, em tal período, diante da palavra “ciência” se curvavam, reverentes, os mais fortes espíritos.

É importante mostrar que o solo de Bergson, além de ter sido preparado por Kant e cultivado por Comte, também fora anteriormente regado por Descartes. Apesar de Descartes intuir o cogito como princípio absoluto, não se pode desconsiderar esse pressuposto como o próprio ideal de racionalidade. O cogito cartesiano é um ponto de referência para o fazer científico moderno, tendo como paradigma o rigor matemático e a rigidez lógica. Não deixa de ser curioso observar o quanto não somente Bergson, mas também Husserl, foram sistematicamente orientados e formados no circuito das ciências matemáticas. Eram, aliás, matemáticos de formação. Isso para dizer que Bergson se encontrava em uma cosmovisão na qual a matemática ainda era o ideal dos jovens estudantes franceses do século XIX. Jacques Maritain retrata esse cenário intelectual:

\footnotetext{
A primeira formação intelectual e os primeiros estudos de Bergson seguiram muito de perto o triunfo oficial, celebrado nos anos 60 e 70, do ateísmo e do materialismo no pensamento europeu; então o orgulho da inteligência e da ciência dita positiva deixa-se inflamar no fogo de sua glória; sob a influência de Comte, de Litré, de Renan. Esperava-se tudo do futuro da ciência e do reinado dos sábios, e Berthelot resplandecia aos primeiros raios desta apoteose. (MARITAIN, 1948, p. 310).
}

\footnotetext{
${ }^{3} \mathrm{O}$ ano do nascimento de Henri Bergson é datado de 1859, dois anos após a morte do pai do positivismo. Isso para dizer que a recepção histórico-cultural de Bergson já veio minada pelo teor empírico de se fazer ciência, pois a humanidade, em seu aspecto cognitivo, já teria alcançado seu terceiro estágio evolutivo.
} 
Vemos, então, Bergson inserido em um ambiente cercado por uma cultura de base cientificista sob a égide da racionalidade lógico-matemática. Vislumbrava até certa espiritualidade de teor materialista, cuja ciência empírica ocuparia o lugar de oráculo, estipulando verdades enfáticas às totalidades das áreas do saber. Nesse contexto, Bergson não é alheio ao seu tempo, sendo fortemente influenciado com o pensar científico da época. Prova disso é o fato de ele ser um intelectual que, a todo instante, dialoga com as ciências, mostrando-nos a estreita relação da filosofia com elas.

Sendo assim, como já frisado, seus primeiros estudos foram orientados para pensar a rigidez do fazer científico, tendo como base o rigor do pensamento matemático. Durante seus primeiros anos como estudante no Liceu Fontanes, sua dedicação ao ensino da matemática lhe possibilitou o primeiro prêmio do Concurso Geral (Concours Général). Diretamente envolvido nesse ambiente, é de crer que o interesse de Bergson, como jovem entusiasmado com o progresso do conhecimento científico, fosse pensar a filosofia acompanhada por aquele progresso, ou seja, que ocupasse ou aspirasse ao estatuto de ciência.

Esse entusiasmo intelectual faz com que o jovem Bergson seja um apaixonado pelas ciências naturais, interessado, sobretudo, em estudar o que fosse tangente à psicologia como também à biologia e aos aspectos evolutivos. Tais áreas de conhecimento, na verdade, deixam marcas indeléveis em sua filosofia. É assim que o filósofo, no entanto, flertará com a química mental de Stuart Mill e, principalmente, com o evolucionismo filosófico de H. Spencer. Fato é que Bergson fora despertado para a filosofia de Spencer por certo ideal de precisão. Sentia que nas conjecturas das abordagens especulativas faltava um elo entre teoria e prática, ou seja, que os conceitos desenvolvidos pelas filosofias precedentes pudessem ser referenciados com a própria realidade. Segundo nosso autor: "[...] o que mais faltou à filosofia foi a precisão", e acrescenta: "Os sistemas filosóficos não são talhados na medida da realidade em que vivemos. São largos demais para ela” (BERGSON, 2006a, p. 3).

Seria então Spencer que teria, em sua filosofia, a precisão necessária que almejava Bergson? Seria ele que, na qualidade de filósofo da evolução, teria abordado os verdadeiros problemas tangentes à vida? Aos olhos de Bergson, Spencer apresentava um sistema no qual os vazios da abstração seriam preenchidos com a concretude da própria vida. Suas explicações científicas seriam, enfim, guiadas pela particularidade dos fatos, bem como pela evidência da precisão rigorosa. A filosofia de Spencer parecia, no entanto, fazer exceção: "Uma doutrina, outrora, pareceu-nos fazer exceção, e é provavelmente por isso que a ela nos havíamos prendido em nossa primeira juventude" (BERGSON, 2006a, p. 4). Bergson, 
contudo, também percebe o reducionismo dos Primeiros Princípios, uma vez que essa obra ainda se apoiava em generalizações vagas. Observa Bergson que as ideias últimas da mecânica não teriam sido aprofundadas. Assim, portanto, trabalhar esse déficit da doutrina de Spencer talvez possibilitasse ao próprio Bergson elevar-se a um patamar de precisão filosófica. A questão é que nosso pensador francês se incumbe da missão de preencher as lacunas deixadas por Spencer. À medida que foi explorando o programa spenceriano, ele se deparou com a ideia de tempo: "Ali, uma surpresa nos esperava” (BERGSON, 2006a, p. 4), examina ele. Ao invés de se aprofundar em Spencer, o resultado foi se afastar dele.

A surpresa de Bergson soa como decepção frente à filosofia do evolucionista, pois ali percebeu que Spencer se propusera a falar de um evolucionismo, mas esse não abarcava a evolução, já que ignorava o tempo real, que é a base para toda teoria da evolução: "Muito nos impressionou, com efeito, ver como o tempo real, que desempenha o papel principal em toda filosofia da evolução, escapa à matemática" (BERGSON, 2006a, p. 4). Spencer teria preparado um primoroso projeto; contudo, seu fracasso estava em não se apropriar do tempo que realmente permite a evolução. Em vista disso, Bergson questiona: "Mas como compreender que a filosofia de Spencer, doutrina de evolução, feita para seguir o real em sua mobilidade, seu progresso, sua maturação interior, possa ter fechado os olhos àquilo que é a própria mudança?" (BERGSON, 2006a, p. 6)

Estava Bergson descobrindo um novo tempo, estava entrando no domínio de uma percepção da vida interior, dos acontecimentos mais reais que vão além das "verdades" estabelecidas pelo positivismo. Tratava-se de uma experiência íntima do tempo real, diferentemente daquela em que Spencer se apoiava. Esse tempo não apresentava partes justapostas umas às outras, sendo assim indivisível. O tempo que despertou o interesse de Bergson era um tempo vivo cuja essência consistia em passar. O tempo é, em si, mobilidade constante. Diferentemente do tempo matemático, que, na opinião do filósofo, analogicamente é compreendido como uma linha, o tempo que se vislumbra agora é fluidez contínua: "A linha que medimos é imóvel, o tempo é mobilidade. A linha é algo já feito, o tempo, aquilo que se faz e, mesmo, aquilo que faz de modo que tudo se faça" (BERGSON, 2006a, p. 5).

O elemento mais categórico, diríamos, da existência, no qual toda teoria da evolução deveria se sustentar escapa aos olhos de Spencer; por outro lado, a perspicácia de Bergson restitui ao tempo seu sentido mais originário, isto é, seu estado de durée. Diríamos, portanto, que Bergson, com tal atitude, dá início à ruptura de paradigmas de orientação positivista, pois, ao teorizar um modelo de tempo que até então se fazia estranho às abordagens científicas da 
época, acaba por possibilitar ver, sob outro prisma, a essência do tempo, que é um desenrolar contínuo, um fazer-se constante.

Visto que, na conjuntura dos elementos que compõem os modelos científicos, o critério de verdade das ditas ciências positivas é a verificação por meio de medidas, o que Bergson apresenta foge ao entendimento da astuciosa ciência em voga. Cabe ressaltar que, diversamente dos laboratórios científicos, o campo de percepção do tempo real é a própria consciência. Assim, o tempo, como é descrito por Bergson, passa a ser primeiramente uma realidade da consciência; de outro modo, a consciência é o campo que possibilita a experiência originária do tempo como duração. Trata-se de uma experiência pessoal, de uma manifestação de fenômenos no domínio da consciência, sintetizados como duração pura, isto é, multiplicidades qualitativas que se interpenetram e se mostram como um todo desprovido de qualquer noção de espaço. A respeito disso, Bergson se posiciona:

\footnotetext{
E se investigássemos o que ela é? Como apareceria ela para uma consciência que quisesse apenas vê-la, sem medi-la, que apreenderia então sem detê-la, que por fim se tomaria a si mesma como objeto e que, espectadora e atriz, espontânea e refletida, reaproximasse, até fazer com que coincidam, a atenção que se fixa e o tempo que foge? (BERGSON, 2006a, p. 6).
}

A duração seria o próprio acontecer do tempo dado à consciência. Vivê-la consiste em experimentar a si mesmo, ou seja, experienciar a consciência como um fluxo que se sintoniza num tempo que ali transcorre. É nessa perspectiva que, à maneira de Bergson, a duração assume um gesto de acontecimento, uma manifestação do próprio ser, pois trata-se de uma síntese do acontecer temporal manifesto à consciência, não cabendo a ela, portanto, ser determinada e muito menos mensurada. A ela cabe, apenas, uma palavra: ser vivida. $\mathrm{O}$ que se percebe na descrição bergsoniana da duração como acontecimento de um tempo manifestado na consciência? Ora, essa simbiose entre tempo e consciência se compreende como um fluir dos estados internos manifestos em si mesmos? Como não entender que uma consciência que percepciona a si própria não pode ser uma consciência aberta para acontecimentos fenomenológicos?

Tais questões passam a se tornar relevantes a fim de situar o movimento que Bergson realiza, desprendendo-se de uma mentalidade positiva, para, enfim, entrar no curso dos acontecimentos da vida no que ela tem de interior a si mesma. Como ele nos diz: "Tal era a questão. Com ela, penetrávamos no domínio da vida interior, pelo qual até então nos desinteressamos" (BERGSON, 2006a, p. 6). Assim, Bergson se desvencilhava de sua influência juvenil, pondo em questão os princípios das concepções materialistas, 
associacionista e evolucionista, no intuito de salvaguardar uma experiência da duração depurada dos preconceitos positivistas.

Uma longa série de reflexões e de análises nos fez afastar um por um esses prejuízos, abandonar muitas ideias que havíamos aceitado sem crítica; finalmente, acreditamos reencontrar a duração interior totalmente pura, continuidade que não é nem unidade nem multiplicidade, e que não entra em nenhum de nossos quadros. (BERGSON, 2006a, p. 6).

A ruptura com a cultura cientificista tornou-se, pois, necessária, visto que os postulados epistêmicos vigentes não abriam uma experiência profunda da vida interior. Dessa forma, diznos Martins: "Havia de romper com o associacionismo, com o positivismo de Comte e com o agnosticismo de Spencer, e, mais que tudo, com o relativismo de Kant e dos kantistas" (MARTINS, 1946, p. 24). Assim, o solo seguro da ciência em que Bergson se encontrava foi abalado, de modo que não podia mais ali permanecer. Sua atitude foi olhar para além do positivismo, visando acercar a verdadeira dimensão do real ignorada por aquela compreensão. O caminho para a vida do espírito (vivência de estados interiores) seria seu próximo passo ou, mesmo, a possibilidade de superação dos impasses cientificistas. O problema é que a solução cientificista se tornava cada vez mais dogmática, já que o método experimental penetrara os domínios do estudo da consciência. O projeto de naturalizá-la tornava-se inquestionável, uma vez que sua pretensão era tratá-la pelo mesmo viés metodológico das ciências empíricas, como se ela fosse, também, um objeto das ciências naturais, um dado não imediato, mas, sim, mediado empírico-matematicamente.

Contra esse projeto de naturalização da consciência teria tomado curso na França, tempos antes de Bergson, uma corrente de pensadores dispostos a retomar a atitude de auscultação iniciada por Plotino. No século XVIII, Maine de Biran tornara-se o maior representante do movimento que acenava para uma experiência espiritual da vida interior, movimento esse denominado "espiritualismo". Pois bem, essa influência também teria levado Bergson a perceber as incongruências do positivismo, uma vez que a filosofia de Biran era o caminho no qual realmente deveria caminhar a metafísica:

Desde o início do século, a França teve um grande metafísico, o maior que ela produziu desde Descartes e Malebranche: Maine de Biran (1766-1824). Pouco notada no momento em que apareceu, a doutrina de Maine de Biran exerceu uma influência crescente: podemos perguntar se a via que este filósofo abriu não é aquela na qual a metafísica deverá caminhar definitivamente. (BERGSON, 2006b, p. 264 265). 
Bergson, a esse modo, seria conduzido para uma filosofia mais viva, tangente ao domínio do espírito. Juntamente com Biran, outros pensadores também inspiram Bergson, como Ravaisson, Lachelier e Boutroux ${ }^{4}$. Se não foram aqueles filósofos que teriam dado suporte para Bergson romper com as filosofias hegemônicas de seu tempo, a eles se deve pelo menos a inspiração de ver que há mais no espírito do que na matéria, ou seja, de perceber que, além de possíveis verdades determinadas em um campo empírico, existe o domínio da liberdade, o âmbito próprio de uma consciência que percepciona o tempo em seu desenrolar, tempo que pode ser vivenciado mediante um contato íntimo consigo mesmo. Tratam-se de filósofos que teriam impulsionado Bergson para formular sua filosofia em um âmbito espiritual, o que, em certo sentido, termina por caracterizar a filosofia bergsoniana da intuição.

É inegável que a figura de Biran tenha sido significativa para Bergson, como é incontestável que Bergson tenha bebido da torrente do espiritualismo por aquele defendido. Aliás, quando Bergson fala de um contato com a realidade interior via intuição, já um século antes Biran teria tratado d'A Percepção Interna de sua Existência, em seu Ensaio sobre os Fundamentos da Psicologia. Nesses trabalhos, Biran busca priorizar a experiência interior. Esse fato, por si só, atesta o quanto a teoria da intuição descrita por Bergson revela traços da filosofia biraniana, cujo entendimento real está na posse de nós mesmos por uma certa introspecção. A forte influência de Biran teria despertado Bergson das tendências de tratar o campo da consciência no que toca às vivências profundas a partir de um método experimental. É principalmente contra essa tendência que Bergson irá inclinar seu pensamento.

Sendo assim, vemos que o terreno espiritualista deixou marcas profundas em Bergson. Ora, isso se justifica pelo contato que nosso autor teve com a filosofia de Maine de Biran. Diante disso, teriam razões aqueles que defendem que Bergson é um espiritualista? Bergson seria, no entanto, o sistematizador de Biran na escola do espiritualismo? Acreditamos que Bergson não teve esse interesse, tampouco de se limitar a um território discursivo puramente

\footnotetext{
${ }^{4}$ Ravaisson, Lachelier e Boutroux seguiam a linha de pensamento de Biran desempenhando o papel de críticos, principalmente do mecanismo que dava suporte à rigidez do cientificismo. Eles buscavam, sobretudo, suscitar o âmbito mais íntimo tangível: o da liberdade. Bergson, todavia, não esconde sua admiração por esses autores. $\mathrm{O}$ que não seria demais dizer é que o seu contato com eles contribuiu, de alguma forma, com sua inclinação para o caminho de uma filosofia do élan. Exemplo disso é o lugar reservado, numa parte de $O$ Pensamento e o Movente, para uma exposição de A Vida e A obra de Ravaisson, levando-nos a identificar sua real aproximação com esse filósofo, sobretudo no que diz respeito ao procedimento metodológico ravaissiano com a filosofia. Bergson o identifica como "[...] método de unificação verdadeira" (BERGSON, 2006a, p. 266). É de crer que o método referido é o que Bergson chamou de intuição filosófica, já que, por meio dela, "[...] o universo visível nos é apresentado como o aspecto exterior de uma realidade que, vista de dentro e apreendida em si mesma, nos apareceria como um dom gratuito, como um grande ato de liberdade e de amor" (BERGSON, 2006a, p. 282). Eis o que propunha mostrar Ravaisson.
} 
idealista, como uma espécie de refúgio da realidade externa. Sua real preocupação era salvaguardar o caminho espiritual e, por este, desenvolver um método que apontasse para um modo de compreensão para além da experiência obscurecida pelo positivismo. Cabe, entretanto, explicitar que o que Bergson faz de maneira alguma pode ser confundido com um idealismo que ignora a matéria. Sobre isso, Franklin Leopoldo atenta: "O equívoco é pensar que o espírito se afirma evitando a materialidade, quando na verdade ele se afirma sobre a materialidade e através dela" (SILVA, 1994, p. 338). O espírito que aparece na filosofia de Bergson não caminha para além da matéria. Na verdade, sua concepção é de um espírito que se afunda na própria matéria, portanto de modo algum coaduna com uma forma de idealismo metafísico alheio, inteiramente, à experiência do real. As evidências que temos nos fazem ver que, mesmo que Bergson tome como pano de fundo de sua filosofia o método de Biran, ainda se diferencia dele. Seus horizontes em alguma medida se distanciam, pois Biran buscava um conhecimento interior da realidade interior, enquanto que Bergson se encaminhava para o conhecimento interior da realidade exterior.

Vemos, portanto, Bergson se situar entre duas tendências: uma positivista e outra espiritualista. Apesar de ambas se tornarem base para seu pensamento, percebe-se que ele não se restringe a nenhuma delas, visto que elas apresentavam certas incongruências. Bergson tão logo propõe formular seu pensamento para além desses limites ou escolas. Isso the garante uma autonomia no modo de filosofar, possibilitando inaugurar uma filosofia nova e pertinente à comunidade filosófica.

Associar Bergson ao "bergsonismo" incutido pelas convicções apresentadas pelos intérpretes de Bergson, sem dúvida é um equívoco que salta aos olhos. O genuíno pensamento de Bergson se delineia rumo à experiência real do vital que perpassa o campo das vivências reais (consciência) e a totalidade da existência (estrutura ontológica do tempo que se faz duração). O "bergsonismo" parece ter fechado os olhos para aquela peculiaridade do pensamento do autor, enaltecendo questões que pouco têm a ver com o projeto bergsoniano: restaurar as coisas em sua essência a partir da experiência concreta da duração. Assim, a proposta que deixamos é que um olhar mais atento ao pensamento do autor seja priorizado, uma vez que sua filosofia vai além das exegeses que insistiram em aliar o genuíno pensamento de Bergson com o dito "bergsonismo". 


\section{REFERÊNCIAS BIBLIOGRÁFICAS}

BERGSON, H. Ensaio sobre os dados imediatos da consciência. Tradução de João S. Gama. Lisboa: Edições 70, 1988.

O pensamento e o movente: ensaios e conferências. Trad. Bento Prado Neto. São Paulo: Martins Fontes, 2006a.

. A filosofia francesa. Trad. Silene Marques. In: Revista Trans/Form/Ação, São Paulo, 29(2): 257-271, 2006b.

. Matéria e memória: ensaio sobre a relação do corpo com o espírito. Trad. Paulo Neves. São Paulo: Martins Fontes, 2006c.

CHEVALIER, J. Conversaciones con Bergson. Trad. José Antonio Miguez. Madrid: Aguilar, 1960.

GILLOUIN, R. La philosophie de M. Henri Bergson. Paris: Bernard Grasset, 1928.

MARITAIN, J. La philosophie bergsonienne. Paris: P. Téqui, 1948.

MARTINS, D. Bergson: a intuição como método na metafísica. Porto: Livraria Tavares Martins, 1946.

MERLEAU-PONTY, M. Phénoménologie de la perception. Paris: Gallimard, 1945. Éloge de la philosophie. Paris: Gallimard, 1953.

. Signos. Trad. Maria E. Galvão Gomes Pereira. São Paulo: Martins Fontes, 1991. . Parcours deux (1951-1961). Lagrasse: Verdier, 2000.

SARTRE, J-P. Situations I: essais critiques. Paris: Gallimard, 1947.

. A imaginação. Trad. Luiz Roberto Salinas Fontes. 5. ed. São Paulo: Difel, 1980.

. O ser e o nada: ensaio de ontologia fenomenológica. Trad. Paulo Perdigão. 20. ed.

Petrópolis, RJ: Vozes,

SILVA, F. L. Bergson: intuição e discurso filosófico. São Paulo: Loyola, 1994. 